\title{
A Case of Auricular Chondroma
}

\author{
Yongsug Choi, Hana Choi, Kyung Suk Jin and Jeong-Hoon Oh \\ Department of Otorhinolaryngology-Head and Neck Surgery, The Catholic University of Korea College of Medicine, Seoul, Korea
}

Received November 10, 2013

Revised December 5, 2013

Accepted December 8, 2013

Address for correspondence Jeong-Hoon Oh, MD

Department of Otorhinolaryngology-

Head and Neck Surgery,

The Catholic University of Korea

College of Medicine,

180 Wangsan-ro, Dongdaemun-gu,

Seoul 130-709, Korea

Tel +82-2-961-2148

Fax +82-2-959-5375

E-mail_ojhent@catholic.ac.kr
Extraskeletal chondroma is a rare benign tumor that develops in the soft tissues, and it manifests as a solitary subcutaneous nodule or a slowly growing tumor. It occurs preferentially in the hand and foot area of adults, and the development in the auricle is very rare. We report a rare case of chondroma that developed in the auricle, which were treated with wedge excision and reconstructed using a Burow's triangle, with a review of the literature.

Korean J Audiol 2013;17:156-158

KEY WORDS: Extraskeletal chondroma $\cdot$ Auricle $\cdot$ Helix reconstruction $\cdot$ Burow's triangle.

\section{Introduction}

Extraskeletal or soft-tissue chondroma is a rare benign cartilaginous tumor that develops in the soft tissues without bone or joint involvement, occurring predominantly in the hands and feet of adults in their third and fourth decades of life. ${ }^{1)}$ Clinically, it manifests as a slowly growing subcutaneous nodule, and the diameter is less than $3 \mathrm{~cm}$ in most cases, with a development in the facial area reported very rarely. However, the presence of this tumor has been described in the head and neck region, mainly in the tongue, and less likely in the cheek, neck, parotid gland, parapharyngeal space, masticatory space, and masseter muscle, ${ }^{2)}$ with the age of onset usually between $30-$ 60 years of age. The case presented here is of a particular interest because of the exceptional location of the tumor, and a matter of reconstruction of a defect after the removal. We were unable to find any analogous report in the literature except for only two reports describing cases of extraskeletal chondroma in the auricle. ${ }^{2,3)}$ In the presenting case, we report a rare case of chondroma that developed in the auricle, which were treated with wedge excision and reconstructed using a Burow's triangle.

This is an Open Access article distributed under the terms of the Creative Commons Attribution Non-Commercial License (http://creativecommons. org/licenses/by-nc/3.0/) which permits unrestricted non-commercial use, distribution, and reproduction in any medium, provided the original work is properly cited.

\section{Case Report}

52-year old male patient visited our clinic presenting with an unilateral mass of the auricle for several years. Physical examination revealed a $1.5 \times 1.5 \mathrm{~cm}$ sized painless, hard mass accompanying a nodular irregularity, located on the superior portion of the helix (Fig. 1). Surgical removal was performed under a local anesthesia. A $1.0 \times 0.8 \mathrm{~cm}$ sized firm, round, and well-encapsulated mass was completely removed by wedge excision (Fig. 2A), and the remaining defect was approximated with a creation of Burow's triangle in the scapha (Fig. 2B, C). Histopathologic examination revealed a mass consisted of an acidophilic hyalinized matrix with cartilage cells scattered among them, and in the center, local calcification was observed. Tumor cells had cytoplasms with a distinct border, and the nuclei were of a circular or an oval form; atypical or abnormal mitosis was not observed (Fig. 3). There was no recurrence at the 12-month follow-up.

\section{Discussion}

Histologically, extraskeletal or soft-tissue chondroma is a lobulated nodule surrounded by a fibrous capsule filled with mature hyalinized cartilage tissue, with no association of underlying bone. ${ }^{1,4)}$ Association with secondary degeneration 
within the matrix, such as cystic change, ossification, fibrosis, mucinous change, and calcification as in the presenting case, requires differentiation from other soft-tissue tumors. The diseases to be differentiated include tumoral calcinosis, calcifying aponeurotic fibroma, ectomesenchymal chondromyxoid tumor, and chondrosarcoma. ${ }^{5,6)}$ The etiology of extraskeletal chondroma is uncertain. The following are 3 hypotheses that have been proposed. ${ }^{2)}$ The first hypothesis suggests of the cartilage cells originated from the skeletal structure migrating to the adjacent connective tissue; the second proposes a conversion of the precartilaginous tissues that are in the ligament attachment area at the activation period; the last hypothesis proposes a metaplasia of synovial cells differentiating as cartilaginous cells.

Treatment for chondroma usually involves wide local resection. It may recur in $10 \%$ to $15 \%$ cases; nevertheless, even in
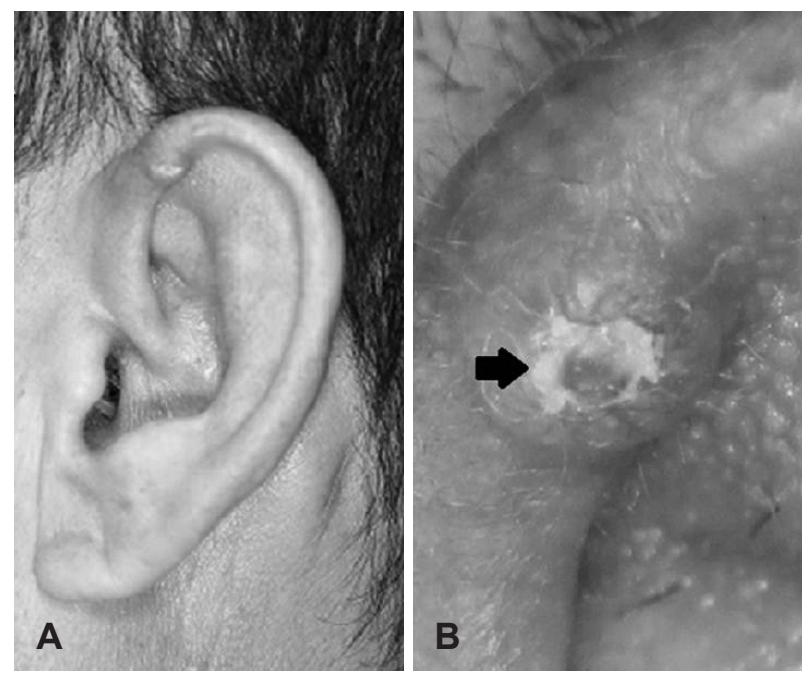

Fig. 1. A: Preoperative photograph shows a $1.5 \times 1.5 \mathrm{~cm}$ sized painless hard mass located on the superior portion of the helix. B: Accompanying nodular irregularity (black arrow) was noted in the mass. recurred cases, local resection is sufficient. ${ }^{1,2)}$ However, excision of the tumor located in helix of the auricle requires a reconstruction of the defect, if it is bigger than 1 to $1.5 \mathrm{~cm}$. Many techniques have been described to treat a defect of the helix secondary to tumor excision, and the advancement of the helix by placing a Burow's triangle in the scapha is preferred whenever possible. In the presenting case, the defect measuring $1.5 \mathrm{~cm}$ in diameter, was successfully reconstructed with advancement of the helix using a Burow's triangle in the scapha. No irregularity in form and contour was observed dur-

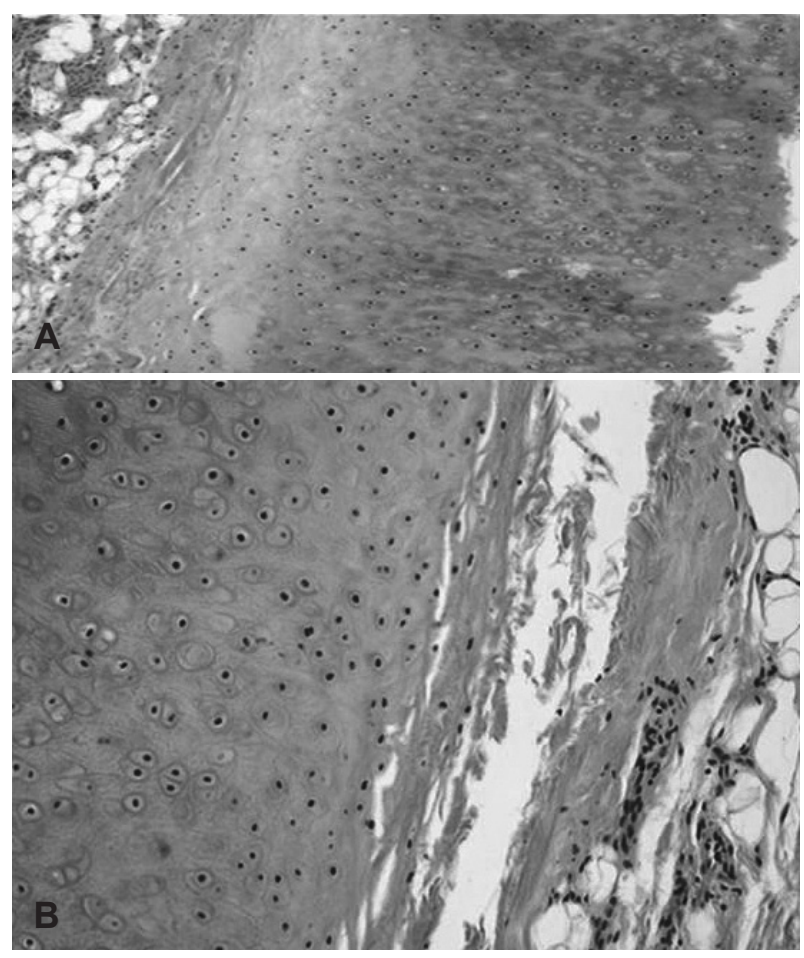

Fig. 3. Histopathologically. A: The tumor consists of hyaline cartilage and collagenous fibrous tissue (H\&E stain, $\times 40)$. B: The hyaline cartilaginous tissue contains homogeneous chondrocytes with round nuclei and chondrocytic lacunae (H\&E stain, $\times 200)$.
Fig. 2. Intraoperative images. A: Design of Burrow's triangle (black arrow). B: Upon a complete removal of the tumor, the defect was reconstructed with using of a Burrow's triangle (black arrow). C: Postoperative image.

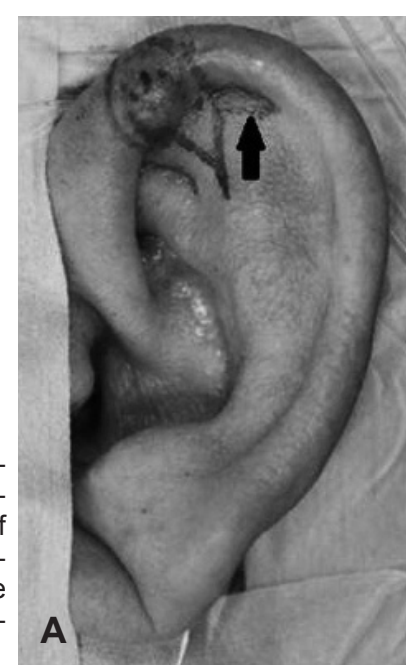

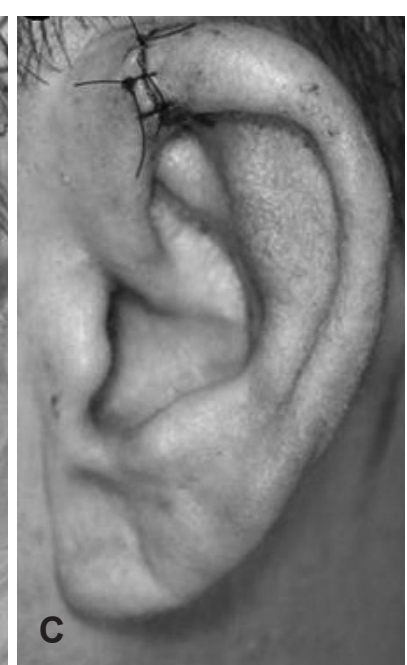


ing a postoperative follow-up.

We report a case of a very rare extraskeletal chondroma that occurred in the auricle with a review of the literature.

\section{REFERENCES}

1) Watanabe F, Saiki T, Ochochi Y. Extraskeletal chondroma of the preauricular region: a case report and literature review. Case Rep Med 2012;2012:121743.

2) Kwon H, Kim HY, Jung SN, Sohn WI, Yoo G. Extraskeletal chon- droma in the auricle. J Craniofac Surg 2010;21:1990-1.

3) Quercetani R, Gelli R, Pimpinelli N, Reali UM. Bilateral chondroma of the auricle. J Dermatol Surg Oncol 1988;14:436-8.

4) Kransdorf MJ, Meis JM. From the archives of the AFIP. Extraskeletal osseous and cartilaginous tumors of the extremities. Radiographics 1993;13:853-84.

5) Chung EB, Enzinger FM. Chondroma of soft parts. Cancer 1978;41: 1414-24.

6) Allen CM. The ectomesenchymal chondromyxoid tumor: a review. Oral Dis 2008;14:390-5. 